\title{
Reino de hombres, mundo animal: presencia animal en la narrativa breve de Antonio Di Benedetto
}

\author{
Fabiana Inés VARELA \\ Universidad de Cuyo-CONICET
}

\begin{abstract}
RESUMEN
La presencia de animales, tanto domésticos como salvajes, es una constante en la narrativa del escritor argentino Antonio Di Benedetto. Esta presencia de los irracionales asume funciones diversas, a la par que va configurando una suerte de simbología personal cuyo sentido, intrínseco a la obra pero también en relación con la cultura universal, puede aún ser profundizado desde diversos ángulos. En este sentido, se pretende ahondar en la significación simbólica de los animales presentes en la narrativa breve de este autor, a fin de iluminar tanto la interpretación de su densa obra como la de su poética.
\end{abstract}

Palabras clave: Antonio Di Benedetto, simbolismo, animales, narrativa argentina.

\section{Kingdom of Men, Animal World: Animal Presence in Antonio Di Benedetto's Shorts Stories}

\begin{abstract}
The presence of animals, both domestic and wild, is a constant in the narrative of the Argentine writer Antonio Di Benedetto. The presence of the irrational assumes various functions, while it shapes a kind of personal symbolism, whose meaning, intrinsic to the work, but also in relation to universal culture, may still be deepened from different angles. In this sense, it intends to delve into the symbolic significance of the animals on the brief narrative of the author, to illuminate the interpretation of his dense work as well as that of his poetics.
\end{abstract}

Keywords: Antonio Di Benedetto, symbolism, animals, Argentinian fiction.

SUMARIO: 1. Los animales en la obra dibedenettiana. 2. Violencia canina. 3. Clarividencia felina. 4. La emanación de lo inconsciente: ratones, pájaros, insectos. 5. Reino de hombres, un mundo animal. 6. Bibliografía. 
La presencia de animales, tanto domésticos como salvajes, es una constante en la narrativa del escritor argentino Antonio Di Benedetto ${ }^{1}$. Su primer libro, Mundo animal (1953) posee un sugerente título que plantea de modo temprano una clave interpretativa de su obra. Con significaciones simbólicas y funciones diversas, el mundo animal está presente en la mayor parte de sus novelas y relatos breves, configurando así una suerte de simbología personal cuyo sentido, intrínseco a la obra pero también en relación con la cultura universal, puede aún ser profundizado desde diversos ángulos.

La crítica no deja de señalar la importancia de los animales a lo largo de toda la obra de Di Benedetto, su atracción permanente hacia el misterio del mundo de los irracionales. Si bien el mismo autor señala, en un texto introductorio a la segunda edición de Mundo animal, su relación inicial con la fábula: "Esos cuentos son fábulas; los irracionales asumen personificaciones; el libro lleva propósitos moralistas" ("Borrador de un reportaje": 9), la mayor parte de los estudios (Boldori, Maturo, Corro, Filler, Castellino, Néspolo) observan un alejamiento de esta función tradicional y un progresivo acercamiento simbólico de lo animal hacia las zonas oscuras, ocultas y a menudo atemorizantes del ser humano. Asimismo, el carácter dual de los animales, transparentes del comportamiento humano, oscila permanentemente entre el Bien y el Mal, ya como fuerzas protectoras ya como elementos agresivos y violentos. De este modo, el carácter bisémico propio de la fábula pierde fuerza y los significados se complejizan acercándose progresivamente al símbolo.

Dos estudios críticos se centran de modo exclusivo en la simbología animal presente en la obra de Antonio Di Benedetto. Malva Filler, desde la perspectiva de la psicología profunda de corte junguiano, realiza en "Los animales simbólicos de Antonio Di Benedetto" un análisis detallado de los símbolos animales presentes principalmente en el extenso relato "Onagros y hombre con renos". Como imágenes recurrentes en su obra, Filler observa la función del reino animal en su primer libro de cuentos que "coincide con la que le es tradicionalmente asignada por la fábula" aunque la atmósfera que en ellos persiste es "la delirante y obsesiva de los libros de Kafka y del Cortázar de Bestiario" (124). Con respecto a la valoración de lo animal

1 Antonio Di Benedetto, escritor y periodista argentino, nacido en Mendoza el 2 de noviembre de 1922 y fallecido en Buenos Aires el 10 de octubre de 1986. Fue periodista desde muy joven, primero en el diario La Libertad (Mendoza) y, a partir de 1945, en Los Andes de la misma ciudad. En 1956 es nombrado corresponsal y luego supervisor en Cuyo del diario La Prensa (Buenos Aires), del que luego será corresponsal en distintos países de América y Europa. El 24 de marzo de 1976 es detenido por la Junta Militar y recupera su libertad el 3 de septiembre de 1977 gracias a las gestiones de importantes escritores argentinos y europeos como Ernesto Sábato y Heinrich Böll. Ese mismo año inicia su exilio europeo que se extiende hasta 1984 cuando regresa al país luego de restablecida la democracia. Es autor de Mundo animal (cuentos), 1953; El pentágono; novela en forma de cuentos, 1955; Zama (novela), 1956; Grot (cuentos), 1957; Declinación y Ángel (relatos), 1958; El cariño de los tontos (cuentos), 1961; El silenciero (novela), 1964; Los suicidas (novela), 1969; Absurdos (cuentos), 1978; Cuentos del exilio (cuentos), 1983 y Sombras, nada más (novela), 1985. 
en esta primera obra, observa una ambivalencia, pues los animales pueden funcionar tanto como figuras protectoras o como "fuerzas destructivas y atemorizantes", aunque con un marcado predominio de la visión negativa. El análisis de "Onagros y hombre con reno", marca un cambio profundo en la cosmovisión del autor, en tanto los animales "aparecen aquí redimidos en esta reconciliación del hombre consigo mismo" (134).

Mercedes Campos en "Simbología animal dibedenettiana" se centra en el análisis de los símbolos animales que aparecen en la novela Zama, aunque son inevitables las menciones a su obra inicial, Mundo animal. Campos observa que los animales en este libro se relacionan "con la encarnación de lo instintivo, más precisamente de la libido" (3) y que manifiestan, por otra parte, una fuerte carga negativa. También señala la aparición, en menor grado, de los animales como figuras protectoras.

Como ya adelantáramos, el mismo Di Benedetto explicita claves de lectura para desentrañar el valor del mundo animal en su obra. En la primera edición de Mundo animal, en un paratexto inicial, el autor revela la relación bisémica entre lo humano y lo animal que predomina en sus cuentos. Sin embargo, insiste en dejar abierta la posibilidad de otras lecturas más complejas, a cargo del lector:

Yo sugiero; resuelva, de una o más maneras, igual o distinto a mí, quien me lea. Yo diré: El pericote que el hombre alimenta en "Amigo enemigo" es la guerra, justamente la guerra; la "salvada pureza" aludida en la anécdota del Fuci es, sencillamente, la ingenuidad. Usted, lector, puede pensar que sí, que es, pero también puede pensar que no, que no es, porque es, para usted, otra cosa, y esto me tendría muy satisfecho, con la satisfacción de saber que lo mío va más lejos de donde yo pude llevarlo. (8-9)

En la segunda edición, otro paratexto precisa con mayor detalle la correspondencia en los cuentos entre lo humano y lo animal. En primer lugar, el autor señala la relación con el género tradicional de la fábula. Sin embargo, al cerrar este minireportaje y ante el pedido de una "definición ultrasintética" del libro, afirma: "Es un delirio" ("Borrador de un reportaje": 10). Así, a través de la mención de estos estados alterados de la conciencia, señala la emanación de lo inconsciente en sus relatos, posibilitando de este modo la interpretación simbólica, que de hecho la lectura permite.

\section{Los animales en la obra dibedenettiana}

La presencia de animales no sólo es una constante, sino que cumple funciones variadas en la obra de Di Benedetto. En muchas ocasiones, no hay simbolismo posible puesto que los animales están al servicio de la creación de un mundo, como referentes de una realidad de la que la literatura quiere dar cuenta. Esto es especialmente visible en aquellos cuentos de espacio regional, donde los animales salvajes de la zona del desierto o bien los domesticados propios de las zonas rurales son presentados con detallado verismo (Varela, 2007a).

Sin embargo, por su insistente aparición con ropajes imaginarios similares, algunos animales van a tener un valor especial -aunque como ya dijimos ambiguo y 
complejo- en la narrativa breve de Antonio Di Benedetto. Sin pretensiones de exhaustividad, nos detendremos a continuación en algunos de ellos, en general los menos abordados por la crítica y que nos han resultado de particular complejidad. Señalamos, además nuestra atención exclusiva hacia los ejemplos que surgen de su narrativa breve, pues estimamos que en ella están en germen los principales núcleos temático-existenciales de nuestro autor. Juzgamos, además, que su estudio puede arrojar nueva luz no sólo sobre la interpretación de la densa obra de este autor sino también sobre su poética.

\section{Violencia canina}

Una de las presencias animales más constantes a lo largo de la obra de Antonio Di Benedetto es la de los perros. Asociados generalmente a la violencia, aparecen como personajes en numerosos relatos, principalmente en Mundo animal, en los cuentos "Nido en los huesos", "Hombre-perro" y "Reducido". En la primera parte de "Nido en los huesos", los perros matan con saña a un mono que habita en la palmera del patio de la casa del protagonista ${ }^{2}$, mostrando de este modo su bestialidad innata. Sin embargo, es en "Hombre-perro" donde se observa con claridad la ferocidad humana simbolizada por los perros. La frase "hacer una perrada" juega con su sentido en el desarrollo del relato. Un hombre anodino y aparentemente pacífico, da rienda suelta a su brutalidad reprimida cuando encuentra en la calle al hombre que supuestamente le birló su trabajo. Esta ruindad es presentada de modo muy plástico en la metamorfosis del hombre en perro:

Estuve aguardándolo pacientemente, pero cuando lo vi toda la furia me poseyó. Se me hincharon los belfos, me fui al suelo y mis cuatro patas me dispararon hacia él, que ya, advertido rápidamente, en sus cuatro patas también, con un leve aullido de miedo, mostraba, por instinto de defensa, los dientes. Me abalancé sobre su cabeza mordiéndolo con implacable rabia, echando espuma por la boca, tratando de hincarle los dientes en el cuello, que él defendía desesperado con las patas delanteras. (Di Benedetto, 2006: 65)

La violencia del animal, la primacía de su instinto feroz se impone aún sobre otro rasgo atribuido comúnmente al perro, como por ejemplo, la fidelidad hacia su amo. En "Pez" -relato de la colección Absurdos-, el perro llamado "Fiel" vela junto a su ama, postrada e imposibilitada de moverse, en un pequeño rancho en medio del desierto cuyano. La desolación de la mujer, que yace junto al esposo muerto y sufre la constante pesadilla de un pez-pájaro que la acecha, sólo halla atenuante en la compañía del único perro que permanece a su lado: "Desde el patio, los perros la

\footnotetext{
2 “el mono se escondió entre algunos cajones y baúles hasta que los perros, enardecidos por la sangre de un pollo que dio degollado unos pasos agónicos, se le echaron encima sin que nadie se lo impidiera" (Di Benedetto, 2006: 50). Para ordenar la citación, citamos directamente de Cuentos completos, sin embargo consignamos en la bibliografía las distintas ediciones de la obra de este autor.
} 
escuchan, a su manera la siguen, la copian, con lastimero aullido. Pero uno, no. Se escurre, humildito, en la habitación, y va a echarse a los pies de Lumila. Es el Fiel" (Di Benedetto, 2006: 374). Sin embargo, el hambre puede más que la sumisión del animal. La presencia de la sangre fresca de una herida que la mujer se hace en un intento por moverse, despierta el instinto que precipita un final abierto en el que se anticipa veladamente el horror y la muerte:

Recobra debilitados los sentidos y descubre que su perro pasa y repasa su lengua cálida por la herida. Cambian en consecuencia sus impresiones, confiada, y sonríe. Está exhausta y ha quedado tendida de espaldas. Ya se descansa y le dice, con cariño y gratitud:

-Sos mi perro y te llamás Fiel. Bien nombrao, siempre lo supe.

Sin embargo, una evolución acelerada en la forma de lamerle la carne sangrante, abierta por el filo del espejo, la punza de alarme. La lengüetada se ha vuelto áspera, golosa, voraz.

Lumila yergue la cabeza, en busca de algo que desmienta lo que está presintiendo.

Se encuentra con unas fauces, unos ojos que la fuerzan a doblegarse y gemir:

-Fiel, vos sos mi fiel... No me fallés, perrito.

Pero más se le incendia la mirada al poderoso can.

- ¡No me hagás daño, Fielito!

Se lo dice con espanto. Sumisa, como de rodillas. (Di Benedetto, 2006: 378)

Esta imagen del perro asociado a la muerte nos remite, de algún modo, al valor arquetípico del can que es considerado como un psicopompo, guía del alma que se adentra en el más allá, pero además intercesor entre uno y otro mundo y, finalmente, guardián de los infiernos (Chevalier: 816-821).

Esta asociación perro-muerte, además de su consideración como intercesor entre vivos y muertos, aparece de modo sugestivo en dos relatos de corte policial, donde la presencia del perro es un elemento que contribuye a esclarecer el enigma. En "Cínico y ceniza", el perro de un amigo muerto conduce al narrador hacia un mensaje cifrado. Sin embargo, la actitud del animal, en la que se proyecta la misma ambigüedad del personaje protagonista, muestra y oculta a la vez la señal de ultratumba:

El perro, ese maldito Milo, se ha puesto a corretearle por encima y me hace crecer la confusión. Quiere despabilarme, porque ha notado que no avanzo y, tal vez, se ha dado cuenta de mi gesto perdido; pero sus patas y sus uñas, en los entusiastas giros y enviones, destruyen los trazos que labraron el mensaje. [...] Me extraña la quietud en que ha caído el perro. Se me ocurre, con rencor, que él traía una misión: la de impedir que yo llegara a enterarme. (Di Benedetto, 2006: 362)

En "Los Reyunos", un perro llamado Leal, permanece extrañamente junto a una pared de una casa en construcción, donde, al final del relato se descubre que se ha emparedado a la víctima. Estrictamente, el animal acompaña a su amo hasta la última morada, pero su insólita actitud, además de otros indicios del mundo animal como las hormigas, alertan al investigador y le permiten la resolución del crimen. 
En otros relatos, la imagen del perro se asocia a otras áreas semánticas y su simbología se complejiza. Reducido, tal el nombre del personaje que da título al relato homónimo en Mundo animal, es un perro pequeño que habita en los sueños del narrador protagonista, es propiamente su "cuzquito nocturno". Sus notas caracterizadoras lo muestran pequeño y simpático, pero con una ambigüedad propia de los sueños, sueño que, por otra parte, no es estático sino que se transforma sutilmente en pesadilla:

Es, entonces, mi Reducido, como una persistente pesadilla, que vuelve siempre, igual, torturante, y aunque él no puede considerarse de ningún modo una pesadilla y si lo fuera sería una pesadilla simpática, justamente como las pesadillas me tiene el corazón sobresaltado, no en el momento en que se extingue, sino en el día, por la probabilidad, nunca desechable, de que en la noche no vuelva. (Di Benedetto, 2006: 58)

Al parecer positiva, la imagen del perro va adquiriendo perfiles más complejos, que si bien, no totalmente negativos, conllevan una sutil amenaza. Este temor se acrecienta cuando por respuesta al pedido del hombre de que "se traslade [a su] vida despierta", el perro lo invita a que se "vaya con él a los sueños". El final abierto no hace más que aumentar el peligro de disolución latente. El perro puede asociarse en este relato a su simbología universal como intercesor entre el mundo de los vivos y de los muertos pues el sueño es, en última instancia, un espacio que se asemeja a la muerte.

Similar imagen en la que el perro constituye una sutil amenaza para el hombre la encontramos en "Lazarillo de Hermosilla" de la colección Cuentos del exilio. En este caso, el protagonista es un anodino oficinista quien encuentra habitualmente en su recorrido cotidiano, a un mendigo junto a su perro ${ }^{3}$. Es el perro un producto de la fantasía del mendigo: en un diálogo, el narrador pregunta al vagabundo sobre su oficio anterior, ante lo que contesta que era inventor y que su último invento fue el perro.

El mendigo un día desaparece y el perro, sutilmente, va introduciéndose en la vida del personaje. Finalmente, cuando queda cesante en su trabajo, el narrador ocupa el puesto del mendigo y lleva consigo también al perro: "Como nos llevamos muy bien, sigo sin ocupación y su amo no ha regresado, he tomado el puesto de éste, en el túnel para peatones que corre por debajo de la calle Doctor Esquerdo" (Di Benedetto, 2006: 586).

Finalmente, aceptando la pérdida de la dignidad y su última degradación, el hombre ocupa definitivamente el lugar del perro, se transforma en perro: "En cuanto llega a su lugar habitual, el perro, luego de consultarme con la mirada, y ante mi falta

3 "Donde el túnel se achata por debajo de la calzada y de los autobuses, ahí donde se apagan los ruidos, estaba el perro [...]. Adormilado y tendido en el piso de baldosas lo más del tiempo, permanecía su amo. Él no ostentaba al perro, ni tenía el don de la música que explotara haciendo sonar un violín o un acordeón, como tantos lo hacen; ni para solicitar la caridad pública desplegaba un cartón escrito [...]. Su sombrero, boca arriba en el suelo, hacía todo el menester" (Di Benedetto, 2006: 583). 
de respuesta, se echa como de costumbre, pero yo, con voz imperativa, le mando que se alce. Así lo hace. Entonces, ocupo su lugar. Me vuelco en tierra y me echo a ladrar" (Di Benedetto, 2006: 587). No hay aquí violencia, sino degradación del ser, caída en la abyección.

Esta visión negativa de los canes se desarrolla ampliamente en un relato que podríamos considerar como un mito personal de nuestro autor: "Onagros y hombre con renos", de la colección Absurdos. Por medio de un denso entramado de imágenes simbólicas, se narra el periplo de Jonás y su hijo, quienes desterrados del mundo de los hombres, reinstalan un tiempo-espacio mítico en medio de la montaña. Aquí, la primera parte del relato está centrada en el seguimiento de una manada de perros cimarrones que, si bien son una amenaza para los personajes, actúan como guías a través del desierto. Finalmente, los perros atacan a los hombres que pueden hacerles frente con la ayuda de mágicos renos invocados por Jonás ${ }^{4}$.

Sin demorarnos en las múltiples y riquísimas significaciones simbólicas de este relato, podemos detenernos un momento en el sentido negativo que presentan los perros. La presencia y la cercanía de estos animales intensifica los aspectos más perniciosos de los personajes, no en el sentido de su violencia sino de la apatía y la negligencia: "La presencia de los canes nos ha hechizado, nos ha vuelto indolentes y pusilánimes" (Di Benedetto, 2006: 417). Por ello, al desprenderse de su presencia (que no se logra sin violencia ni sin la ayuda espiritual superior de los renos) es necesario cambiar las costumbres: "Tenemos que mudar nuestra costumbres, ahora que nos hemos deshecho del embrujo de esos canes ruines, que tanto he odiado" (Di Benedetto, 2006: 423). Sin embargo, el pasaje al plano superior no se realiza sin una cierta nostalgia, posiblemente de los aspectos más instintivos y salvajes que constantemente acechan al hombre: "Al atardecer, ya colmados los campos de soledad [...], mi padre Jonás emerge, y aúlla, sonoro, gemebundo... y con nostalgia" (Di Benedetto, 2006: 423).

En síntesis, más allá de ciertos aspectos relacionados con la fidelidad y la lealtad, predomina una imagen negativa de los perros asociada, por una parte, a la brutalidad y a la violencia y, por otra, a su faz de guardianes de los infiernos y psicopompos, que se relaciona más claramente con su valor arquetípico.

\footnotetext{
4 “Jonás rompe cabezas, patea, suelta fuego por los dos caños de acero y por la boca, pero

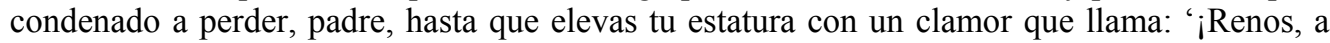
mí!', y todo el aire y los cielos y los perros que aún no hacen caso del grito... todo se anaranja y sé que es el preludio.

Irrumpe el rebaño convocado y hay un momento de batalla, jun momento basta!, en que magníficas astas de cristales recios topan a los canes y los echan a volar como despojos, y los renos pasan y pasan sobre nuestros cuerpos sin causarnos daño, sin peso, sin señales. Los que sobreviven, y son pocos, huyen empavorecidos como de haber visto en cuero vivo al supremo de los antiperros.

Y yo gozo en plenitud de sentirme en el núcleo de una apoteosis que glorifican himnos poseídos de un color naranja" (Di Benedetto, 2006: 429-420).
} 


\section{Clarividencia felina}

La narrativa de Di Benedetto manifiesta una notoria fascinación hacia el mundo de los felinos. La atracción por su belleza, su independencia, su clarividencia se pone de manifiesto en uno y otro relato. Sin embargo, su valor simbólico es complejo, aunque, en líneas generales advertimos, en primer lugar, la presencia del simbolismo universal del gato y por otro, el sentido particular que adquiere el reino animal en Di Benedetto, asociado comúnmente, como ya hemos visto, con la violencia instintiva.

Los gatos son protagonistas u ocupan un lugar central en varios relatos de Mundo animal, y reaparecen luego, con fuerza, en "Felino de Indias" de la colección Absurdos $^{5}$. Los pumas, leopardos y tigres son personajes de diversos cuentos y presentan variados sentidos.

Como arquetipo universal, el gato tiene un simbolismo heterogéneo que oscila entre las tendencias maléficas y benéficas, que pueden explicarse por su actitud socarrona (Chevalier: 524). Tal ambigüedad, veremos, es frecuente en los relatos de nuestro autor.

En algunos cuentos, los felinos, especialmente los gatos, son proyecciones de sentimientos o acciones humanos. Así en "Trueques con muerte" el odio de la mujer que ha perdido su bebé es proyectado de modo directo hacia una gata preñada. El animal sufre pasivamente la agresividad femenina: "A puntapiés la agrede (muda, mordiéndose los labios). Quizás quiere matarla, quizás quiere matarle los nonatos" (Di Benedetto, 2006: 61). La relación de identidad mujer-gato, muy fecunda a nivel de psicología profunda, se despliega solapadamente en el relato pero el análisis de sus ricas implicaciones sobrepasa los límites de nuestro estudio. Esta relación también la podemos observar en Cuentos del exilio, en "Martina espera", donde la identificación del "gato de lujo, de suave y copioso pelaje" con la esposa funciona como una transferencia de ésta hacia el animal cuando el esposo la abandona. Por ello, increpa al gato: "No le gustaste, por eso se fue. ¿Qué iba a hacer aquí, sin un gato que le gustara?".

En otras ocasiones, la relación hombre-gato, apunta a destacar la ambigüedad de ciertas acciones o actitudes. Así en "Volamos" de Mundo animal, el extraño y equívoco gato funciona como metáfora del cinismo de los personajes humanos. Un gato al que "le agrada el agua", que no se sabe "si maúlla o ladra" y, además, vuela no produce maravilla alguna en el narrador que ve en él a "un cínico ejercitado" cuyas acciones no hacen más que reflejar el mundo de mentiras que han construido los personajes humanos: "Debiera maravillarme porque, lo que se cree que es, no es. No puedo. ¿Acaso me maravillo de que tú no seas lo que tu esposo cree que eres? ¿Acaso me maravillo de no ser lo que mi esposa cree que soy? Tu animalejo es un cínico, nada más. Un cínico ejercitado" (Di Benedetto, 2006: 76).

Esta ambigüedad de algunos gatos es fatal para el personaje de un microrrelato enmarcado en el cuento "Falta de vocación": "El gato de la casa tenía cara de bagre.

${ }^{5}$ Los gatos son personajes en "Volamos", "Algo de misterio", "Trueques con muerte" y "Salvada pureza" de Mundo animal y en "Felino de Indias" de Absurdos. 
Se lo decían, le hacían la broma de que lo iban a meter en una pecera. Él acogió la ocurrencia con una vanidad exagerada. Y se puso a presumir de bagre. Otro gato se lo comió" (Di Benedetto, 2006: 123).

También enigmático, si bien en sentido diferente, además de vanidoso y megalomaníaco, resulta el gato narrador de "Algo de misterio". Al comienzo del relato no presenta ningún detalle extraño, salvo el de ser el emisor del discurso. Tanto sus ojos como las actividades que realiza (cazar ratones, noches de amor en los techos) son propios de estos animales. Sin embargo, a medida que discurre el relato, el felino va adquiriendo una dimensión espiritual signada, en primer lugar, por el aprender ("Esta vida, sencilla y clara, [...] no es tan sencilla ni se me está haciendo tan clara. Aprendo, con las películas y con las conversaciones, aprendo"; Di Benedetto, 2006: 86). Este aprendizaje conlleva la incorporación de la cultura y de la capacidad reflexiva. Pero aquí se introduce un discurso megalomaníaco que predomina hasta el final del relato. Interesante es constatar que con la posibilidad de reflexionar aparece también la violencia, en este caso refinada ${ }^{6}$, que luego es sublimada por el arte cuando el gato fantasea sobre la posibilidad de ser un escultor ${ }^{7}$. Esta relación con el arte, finalmente, se sintetiza en un discurso extravagante y al borde del delirio, en el que el animal se considera el autor de una exitosa película, que es para él también una incógnita:

Ahora mismo lo siento yo, siento ya el goce de la incógnita a punto de ser revelación que nunca se revelará $\mathrm{y}$, aun sabiendo que nunca ha de revelarse, se espera que se revele. Me toma, como un manso lago, la voluptuosidad del misterio inofensivo, porque hasta yo mismo desconozco qué nombre usé para firmar el argumento y presentarme como director, e ignoro igualmente cuál es, dónde está, mi excelsa, mi bienaventurada obra de cine. (Di Benedetto, 2006: 88)

El misterio asociado al mundo de los gatos se relaciona con cierta clarividencia animal. Así, en "Felino de Indias" un hombre culpable de un crimen no resiste la mirada insistente de un gato. En este relato, el gato no es ambiguo sino propiamente un gato y sus acciones, tanto en la libertad de la montaña como en la casa, son propias de este animal. Sin embargo, su mirada tiene una sagacidad tal que hace huir al hombre cuya conciencia es culpable: “... descubre los ojos de un gato que alza la cabeza desde el alféizar de la ventana de vidrios. El gato lo estaba mirando y la

${ }^{6}$ La constatación de los prejuicios de algunos padres hacia los gatos lo lleva a reflexiones como: "Podría haber también gatos para los niños. Gatos más grandes que ellos que los mataran aunque los niños se portaran bien y sólo quisiesen jugar con los gatos. De este modo, creo yo, habría después menos hombres desdichados" (Di Benedetto, 2006: 87).

7 "Yo querría hacer una escultura que represente, no al mártir en su integridad, sino el plomo tal como quedó en el cuerpo al enfriarse, y también, por encima de esa tortura de plomo, los ojos del sacrificado. Lo haría, quizás lo haré; pero no acierto a resolver cómo he de suspender los ojos en el aire" (Di Benedetto, 2006: 87). 
mirada hundida en el recién llegado constituye, de un modo terminante, la fría negación del asilo que le han concedido las gentes" (Di Benedetto, 2006: 386).

La ambigüedad, el ser y no ser aparecen también en relación con el gato en "Salvada pureza". Aquí el felino que ha sido gato y es leopardo funciona-al decir del propio autor- como metáfora de la inocencia. En el relato, la metamorfosis del gato en leopardo se asocia con el despertar sexual, como si la sexualidad incitara a una violencia o "indomesticidad" muy marcada que impide al animal seguir conviviendo con los humanos. El final del relato asocia la figura del gato-leopardo con la de un criminal que entra subrepticiamente en la casa. De esta manera, podemos observar la relación entre la madurez, la pérdida de la inocencia y el predominio de la maldad, de la violencia que va caracterizando al hombre en la reflexión continua de Di Benedetto.

Por otra parte, en "El puma blanco", publicado en El cariño de los tontos, el extraño animal albino es el objeto de deseo que mueve el relato. Sin embargo, en el momento de encontrarlo, quienes lo buscan, matan al animal. En este caso, el puma es imagen de la quimera, del deseo siempre insatisfecho que, aun cuando se obtiene, no puede ser disfrutado en plenitud. De modo general, hemos de decir que el puma, felino propio de América, está siempre asociado con la muerte, tanto en "El puma blanco", como en "Caballo en el salitral", relato en el que el puma aparece como depredador natural.

\section{La emanación de lo inconsciente: ratones, pájaros, insectos.}

Compleja es la presencia de ratones que, si bien no tan abundante como la de perros y gatos, plantea una rica y compleja simbología evidente a lo largo de toda la obra de Di Benedetto. Asociado al simbolismo europeo que ve en la rata la imagen de la avaricia, el parasitismo y la miseria, este animal aparece con carácter negativo. No obstante, la relación con el arquetipo cultural no está tan marcada, sino que la presencia de ratones en los relatos destaca la emergencia del inconsciente reprimido (un signo que aparece una y otra vez asociado a lo animal en general) y, de modo más explícito, se asocia con la culpa y la responsabilidad. Por otra parte, observamos también una cierta relación -no totalmente explícita- de la rata con la creación, que es posible de detectar en la interpretación más profunda de algunos relatos.

"Amigo-enemigo" es el primer cuento que en Mundo animal plantea la presencia de la rata, a través del americanismo 'pericote'. Ya desde el título la ambigüedad es manifiesta ${ }^{8}$. Relegado a una caja con libros diversos, el pericote es alimentado por el protagonista con migas de pan hasta transformarse en un monstruoso animal que intenta huir. De esta forma, podemos inferir, en un sentido simbólico, que aquello que

8 Esta atracción-repulsión hacia la rata se observa también en "Hombre invadido" de Absurdos, relato en el que un hombre quiere deshacerse de una rata. También aquí la ambigüedad es evidente y el texto se detiene especialmente en los pormenores de la relación del hombre con la rata y, finalmente, se deja flotando la posible relación con el ser femenino. Por razones de espacio no incluimos el análisis detallado de este cuento. 
relegamos al inconsciente y alimentamos con nuestro propio rencor termina convirtiéndose en un ente monstruoso que se vuelve sobre el propio sujeto. Por otra parte, de modo explícito el relato asocia a esta rata con la guerra: ante la pregunta de una mucama de por qué guardaba en sus bolsillos la miga del pan, el narrador contesta que es para su hijo y luego ante la pregunta sobre el nombre, y en tren de broma ingeniosa, contesta que se llama Guerra y "tiene los años de la humanidad" (Di Benedetto, 2006: 47).

De esta manera, el texto postula la asociación explícita entre el ratón que alimenta el narrador y la guerra que es también alimentada por los hombres. Sin embargo, la pluralidad de sentidos complejiza una lectura únicamente alegórica, en especial una serie de asociaciones que llaman la atención hacia el acto creador'. Tradicionalmente la rata es un animal ctónico, terrestre, subterráneo que fácilmente se asocia a lo inferior, a lo inconsciente, pero también a lo repulsivo y, por lo tanto, reprimible. En el cuento, este ser repulsivo es alimentado, conscientemente, por el hombre que le lleva migas de pan. Además, los libros identificados con la cultura, el pensamiento y la creación, son alimento para la rata que se transforma en "[...] un monstruo repelente y fiero" que cae, al huir de su caja "como un derrame de leche condensada, de puro gordo y graso, de pura miga y papel" (Di Benedetto, 2006: 47).

El monstruo es matado mediante una lapicera (“...sentí en mi mano la lapicera y se la lancé como puñal"), que asociamos claramente a la escritura y la voz perdida del personaje (quien era mudo desde la muerte de su padre) vuelve a escucharse: "El miedo y el asco me forzaban a la lasitud fatal y me forzaron, joh, maravilla!, me forzaron un aliento de voz que yo no sabía qué era y creí sería, deseé que fuese, una flauta" (Di Benedetto, 2006: 48). De esta manera podemos interpretar, y creo que es coherente con la poética de Antonio Di Benedetto, una relación entre los monstruos que genera el inconsciente y que el sujeto trata, infructuosamente de reprimir. La escritura aparece entonces como elemento catárquico que, al nombrar creativamente a tales engendros logra un cierto dominio sobre ellos. Así, la obra de arte literaria puede leerse como una purificación de esos contenidos oscuros que llenan de terror al sujeto, al escritor ${ }^{10}$.

En el cuento "En rojo de culpa", también de Mundo animal, los ratones aparecen asociados a las ideas de culpa y de responsabilidad. Aquí la relación entre las acciones de los ratones y las humanas son menos complejas y ambivalentes. Los ratones no asumen sus culpas sino que buscan a un hombre y le pagan para que sea su chivo expiatorio. El relato se estructura en dos partes claramente diferenciadas. La

9 Esta interpretación, por supuesto, no invalida otras que también surgen del texto, especialmente aquellas que pueden ser abordadas desde el psicoanálisis y en referencia con la figura paterna.

${ }^{10}$ Similar interpretación veremos en "Falta de vocación". También debemos destacar otra línea de lectura posible en la que el animal aparecería asociado a la figura del padre muerto. Esta relación conflictiva con la figura paterna es también una constante en la obra de Di Benedetto. 
primera, de tinte más argumentativo, expone la relación del hombre con los ratones y la culpa. La segunda, más narrativa, da curso a una historia en la que se modifican y tensionan las relaciones entre los ratones y Caín, su culpa paga.

Una gran matanza de ratones, culpables de haber difundido la peste en el seno de una familia, lleva a los animales a descargar su ira contra su culpa paga. No sólo se lo hacen saber, sino que lo atacan y lo obligan a que los devore, poniendo así en imágenes la idea -directriz en el relato- de "ser devorados por su propia culpa": "[...] me desgarraron labios, orejas, nariz, y fueron colmando mi boca y mi garganta y mi estómago. Comprendí. No hubo necesidad de que ninguno más fuera devorado por su culpa, por su culpa paga" (Di Benedetto, 2006: 69).

Pájaros agrediendo a picotazos que devoran, destrozan y despedazan a distintos personajes es una imagen recurrente que transita los relatos breves de Di Benedetto. En "Nido en los huesos" son los buitres los que "[...] inacabablemente voraces [...] han afinado su pico para comerse hasta el último trocito de mi cerebro. Ya en hueso mondo, aún me picotean, no diré con saña, pero como cumpliendo una obligación" (Di Benedetto, 2006: 51). Imagen similar reaparece en "Aballay" de la colección Absurdos. Allí, el hombre penitente que ha jurado expiar su culpa sin bajar de su caballo -a modo de los antiguos estilitas- sufre el asedio de los pájaros en medio de sus pesadillas:

En una parte del sueño hay paz, después cambia en pesadilla: llegan los pájaros. Le caminan por la cabeza y los hombros. Le picotean las orejas, los ojos y la nariz, o quieren alimentarlo en la boca. Hacen nidos, ponen huevos... y él, en todo momento, está muerto de miedo al vacío, donde caerá si se mueve. (Di Benedetto, 2006: 322)

Análoga, aunque menos agresiva es esta otra imagen de los pájaros devorando a un hombre transformado en pan, en el cuento "Es superable" de Mundo animal:

Me reencuentro en las migajas, mis últimos restos, levemente ateridas sobre el pavimento color de ceniza.

Después vendrá el sol, a devolver el dorado a las cascaritas.

Sus destellos atraerán las aves que vengan navegando el cielo y entonces, por sus picos, me elevaré a otra muerte, alada. (Di Benedetto, 2006: 57)

Esta imagen reaparece en Cuentos del exilio: "El padre está panificado. Se vuelve pan, se dora y se seca, se resquebraja. Luego sopla un poco de viento y como el pan se deshace, el aire carga con él y generosamente distribuye las migas a las palomas que entretienen el hambre rondando sobre el techo del aparcamiento de coches" (Di Benedetto, 2006: 539).

En líneas generales, la cultura dota a los pájaros de un simbolismo positivo de tipo trascendente: establecen relaciones entre el cielo y la tierra y son figura del alma, del espíritu, de las funciones intelectuales. Relacionados con los ángeles, simbolizan los estados superiores del ser. El aspecto negativo que entraña lo establece San Juan de la Cruz quien ve al pájaro "como el símbolo de las operaciones de la imaginación, 
ligero, pero sobre todo inestable, volando de aquí para allá, sin método y sin consecuencia... [...] Tal vez por esta razón el Tao reviste a los bárbaros con forma de aves, para designar una espontaneidad primordial, violenta e incontrolada" (Chevalier: 155). Este aspecto lo podemos distinguir en "Nido en los huesos". Aquí se establece una gradación en los pájaros que anidan en la cabeza del personaje. Primero aves canoras ("tuvo gorriones, canarios y perdices dichosos") y luego los buitres que "inacabablemente voraces", "han afinado su pico para comerse hasta el último trocito" del cerebro del personaje. Podemos distinguir, en un plano de interpretación, la imaginación desbordada (las aves cantoras) que el sujeto no puede manejar y por lo tanto, termina convirtiéndose en un elemento agresivo y opositor contra su persona, simbolizado por los buitres.

En la imagen de las aves que con su pico devoran el pan pero también lo elevan, se observa un símbolo ascensional asociado al dolor que conlleva la vida del espíritu. Puede distinguirse en la obra de Di Benedetto el anhelo de un mundo sin libertad, puramente instintivo. Sin embargo, la presencia del espíritu, asociado posiblemente a la moral y a la ética, es vivenciado como una agresión hacia ese paraíso primitivo de pura vida instintiva. Toda elevación del espíritu conlleva una ascesis, una purificación, un dolor que vemos representado simbólicamente en los relatos.

Por otra parte, no podemos dejar de observar que el tema de la violencia es abordado continuamente por Di Benedetto, de un modo sistemático. En esta línea de interpretación, las aves pueden verse como imágenes de la violencia ejercida sobre el sujeto, al igual que los insectos pero con sentido diferente. Los insectos, veremos a continuación, atacan el área afectiva (el corazón) y se relacionan con el amor y las pasiones. En tanto, los pájaros residen en la zona superior, en el área de la inteligencia, en el nivel del espíritu y aludirían, simbólicamente, a una violencia de raíz más consciente, al Mal que realiza el hombre dotado de inteligencia y voluntad.

Un valor eminentemente positivo, incluso religioso del pájaro lo hallamos en "Málaga paloma": relato lírico y de gran estilización, donde la figura del ave es símbolo celeste, de gran espiritualización. Su riqueza de análisis excede los límites de este trabajo, aunque no podemos dejar de señalar las relaciones explícitas más importantes que se establecen en el relato entre la paloma, el espíritu, los simples de corazón ("el tonto de la paloma") y un intertexto pictórico: el dibujo de la paloma de Pablo Picasso ${ }^{11}$.

Con respecto a los insectos, en dos relatos de Mundo animal, se presentan como símbolo de las agresiones externas que poco a poco van invadiendo al sujeto hasta destruirlo. En "Mariposas de Koch", son mariposas blancas trasmutadas en rojo, que representan los escupitajos sanguinolentos del enfermo de tuberculosis. Estas mariposas, a través de la garganta del personaje narrador, se instalan en su corazón, donde hallan morada. La necesidad de volar, inherente a su naturaleza alada, las lleva

${ }^{11}$ Para un análisis más preciso de este texto, remito a mi artículo, "La aproximación al misterio en dos relatos de Antonio Di Benedetto" (Varela, 2010: 15-34). 
más allá, hacia fuera de su corazón y de su cuerpo, hecho que va desgarrando progresivamente al personaje y tiñendo a la vez a las mariposas.

En "Bizcocho para polillas", son también seres alados, -las polillas- quienes comen pacientemente, primero la ropa, pero luego el corazón del protagonista. Éste, por su parte, busca una salida a su situación extrema de hombre desnudo, al que las polillas no permiten vestirse: "Puesto que las polillas comen las superficies manchadas y excavan devorando, les dije que en mi vida había una mancha, localizada en el pecho. De tal manera, calculé, si lograba conmover sus sentimientos, podrían darme la necesaria muerte sin asumir mayores responsabilidades ante su mandante" (Di Benedetto, 2006: 90).

Si bien en "Mariposas de Koch", las mariposas representan la negación de una enfermedad, tanto aquí como en "Bizcocho para polillas" las agresiones de estos insectos pueden asociarse al amor y a la pasión, no siempre correspondida. En "Bizcochos..." la relación es explicita: “... cuando -todavía- pienso en el amor, se me ocurre, ignorando el porqué, que toda mi culpa debe de haber sido ocultarle mi cuerpo" (Di Benedetto, 2006: 90). Sin embargo, en "Mariposas de Koch", la interpretación aludida surge del análisis de una serie de elementos textuales no tan evidentes: la oposición blanco/rojo de las mariposas, el anidamiento en el corazón, la formación de una familia. De esta manera, los insectos pequeños son el amor apasionado que entra subrepticiamente y va devorando poco a poco al sujeto. Observamos, además, que en prácticamente toda la obra de Di Benedetto hay una asociación explícita entre eros y tánatos como dos caras, inseparables, de una misma realidad. Es interesante también el hecho de que sean insectos, animales pequeños, bellos en sí mismos como las mariposas, que no significan mayormente peligro (aunque hay una gradación entre mariposas y polillas y luego, creo que en el mismo sentido con las langostas) los que realicen un ataque que destruye al sujeto.

La langosta, que aparece en relatos posteriores, también se asocia -aunque de modo más sutil- al amor como sentimiento que destruye. En el caso de "Los Reyunos", la presencia de una manga de langosta como inicio del relato, puede ser asociada al amor posesivo del padre-cacique que marca a los suyos y se adueña de todos. La oposición la establece el hijo bastardo quien lo mata por la posesión de una mujer. Aquí, el muerto, Reyes, es la langosta que todo lo devora.

En "Ortópteros", la langosta, la descomunal plaga de langosta es, en primer lugar, el motivo por el cual el periodista llega al pueblo a realizar una nota sobre el devastador fenómeno. Luego, la presencia de estos insectos se asociará también a un extraño personaje y a una supuesta historia de amor que acaba con la muerte de la enamorada.

Las hormigas, por su parte, presentan un doble valor. Por un lado, agreden a los seres humanos, pues en dos cuentos aparecen como carniceras y devoradoras de hombres. En "Sospechas de perfección" de Mundo animal constituyen un pelotón de millones de hormigas que descarnan, le comen toda su carne, al personaje protagónico y en "Los Reyunos", tales insectos van devorando paulatinamente el cadáver del hombre asesinado ("hormiguero viviente, encarnizado en el cuerpo humano enmurado", Di Benedetto, 2006: 466). Sin embargo, en ambos casos resultan 
benéficas. En el primer cuento, el hombre pierde su carnadura pero no su conciencia, razón por la cual un segundo pelotón de hormigas, esta vez voladoras, debe completar su castigo. Sin embargo, el discurso del hombre logra conmoverlas y lo salvan de una muerte segura:

Sucedió: el pelotón se deshizo. Como si una cálida lágrima hubiese llegado a una superficie plana, cambió su forma y se tendió, convertido en convidadora alfombra dispuesta a recibirme y volar. Y voló, llevándome, esa unidad aérea con impulsos de desafío a mi reto y desobediencia a sus mandos, que no sé adónde la conducirían después, pero a mí me condujeron hasta la frontera -que la escuadrilla no decidió trasponer- de otro territorio, definitivamente diferente. (Di Benedetto, 2006: 81)

En "Los Reyunos", por su parte, la observación de los insectos ayuda al investigador a resolver el crimen:

Las miradas del investigador se inclinan sobre la doble columna de hormigas, tan ordenada como ayer, de algún sitio del jardín a la pared más gruesa, y vuelta. El chico las llamó tontas porque no cargaban granos u hojitas. El hombre dice ahora que pueden estar acarreando sustancias más pequeñas, poco visibles; recapacita que no son necesariamente vegetarianas y que incluso hay hormigas salvajemente carniceras, como algunas tropicales. (Di Benedetto, 2006: 466)

Las moscas aparecen asociadas, en un doble juego de atracción/repulsión, tanto a la creación como a la inocencia de la deficiencia mental. En "Falta de vocación" 12 , la visión repulsiva de una mosca y su posterior metamorfosis en murciélago lleva al personaje a enfrentarse con su lado oscuro, oculto y rechazado, asociado en el cuento a la creación literaria. El personaje, sin capacidad de asumir esta dimensión, la niega y se niega a sí mismo la posibilidad de la escritura. La simbología del murciélago: ser definitivamente detenido en una fase de su evolución ascendente, pájaro frustrado (Chevalier: 737), subraya este carácter de fracaso del espíritu, por el temor a hacer frente a los aspectos oscuros del ser.

En "El cariño de los tontos", el personaje de la Colorada, una deficiente, es la única que no tiene repulsión hacia las moscas, sino que por el contrario se siente madre de ellas: "Teme que la Colorada se distraiga de su fantasía que no daña: que ella es madre sólo de las moscas, porque una le entró por la nariz y se le quedó en la cabeza, y ahí cría, y de ahí nacen todas las moscas del pueblo. Y cuando los muchachos le preguntan qué hace con Cataldo, responde con limpia naturalidad: 'Hacemos moscas'" (Di Benedetto, 2006: 257-258). En este caso, su actitud contrasta

${ }^{12}$ Este cuento plantea una interesante dimensión metapoética y relata la historia de un hombre mayor, un jubilado que comienza a escribir y a dar a conocer su producción. Sin embargo, la escritura abre una perspectiva nueva en la que el inconsciente aflora a través de ciertas alucinaciones y sueños que atemorizan al personaje quien prefiere cortar su labor creativa antes que enfrentar los aspectos ocultos despertados por la escritura. 
con la de la protagonista Amaya que se afana en exterminarlas. Podemos distinguir aquí una asociación de las moscas con la sexualidad: la asunción sin complejos de lo instintivo, que es propia de los inocentes, y en oposición el temor, el asco, el rechazo de Amaya hacia esa zona prohibida por la que siente atracción irrefrenable y, a la vez, culpa.

\section{Reino de hombres, un mundo animal}

En este intento limitado por esclarecer el sentido del mundo animal en la narrativa de Antonio Di Benedetto hemos observado no sólo la presencia constante de animales con valor simbólico en su obra, sino también su asociación con aspectos reprimidos por la conciencia, como la violencia pero también la emanación del inconsciente relacionado con la creación y la escritura. A continuación, abordaremos dos fragmentos extraídos de sendos relatos que iluminan esta problemática.

En la reelaboración del cuento "Sospechas de perfección" que se publica en la segunda edición de Mundo animal, se introduce un nuevo párrafo que explicita el sentido del título elegido para la colección:

Soy uno de los sostenedores de este Reino de los Hombres (que apenas es algo más que un Mundo Animal). Que se cobren en mí, las bestias, lo que de ellas despreciamos, condenamos y tememos, mientras en la misma especie humana brota y se ejerce, por individuos, por multitudes, de instante en instante, o por rachas, la ferocidad, la impiedad, la cerrada torpeza, los inmundos o temibles hábitos, el designio tramposo, el ánimo bélico y, en la guerra y la paz, el sentido de destrucción y la voluntad de opresión... (Di Benedetto, 2006: 80-81)

Con claridad, el párrafo señala el punto de contacto entre lo humano y lo animal: aquello que los hombres tienen en sí mismo de irracionales, especialmente la violencia, es proyectado hacia los animales y su instinto. El hombre, más allá de lo logrado en el plano de la civilización no ha podido erradicar los vicios más profundos, especialmente la brutalidad y toda la constelación de conductas que de ella se derivan. Por ello, se homologa en el texto el reino de hombres que no es más que un mundo animal. Pero es tan grande el dolor que le produce al hombre constatar su propia degradación que no puede enfrentarlo y lo proyecta en los animales. Sin embargo, este mecanismo se vuelve contra el mismo hombre, quien al no integrar los aspectos oscuros de su inconsciente, posibilita que afloren con acentuado horror así en las vidas personales como en la historia de la humanidad.

"Sargazos", texto que integra la sección "Tríptico zoo-botánico con rasgos de improbable erudición" de la colección Absurdos, es una reflexión en la que se alternan, entremezclándose, una voz "animal" y una humana que coincide con la del autor implícito. Se trata de una cavilación sobre el misterio que muchas veces lo animal conlleva. Si bien el título alude al mar de los Sargazos, la voz del primer narrador corresponde a las anguilas, especie que preocupó por muchos siglos a los hombres de ciencia. Ellos, al no conocer la redondez de la tierra, no terminaban de comprender su comportamiento migratorio, ya que la especie desova en el Mar de los Sargazos en mitad del océano Atlántico ("Preocupé la mente de Aristóteles, el 
naturalista [...] Preocupo a Aristóteles, naturalista y misántropo, filósofo podría ser, que cavila en Sicilia", Di Benedetto, 2006: 343). En primera persona, el animal detalla su periplo marino. Las citas de autoridad -aquellos antiguos que reflexionaron sobre el comportamiento aparentemente extraño de las anguilas- salpican el discurso, asimismo las alusiones al mítico Aztlán y a la perdida Atlántida.

Sin embargo, hacia el final del discurso, la voz de la anguila es suplantada por la voz del narrador, también en primera persona, que se identifica claramente con el autor ficcionalizado: "Intrigué a un naturalista, acaso filósofo, que se interrogaba en lares de Sicilia. ¡De Sicilia, como Diodoro, como Antonello de Mesina, como Luigi Pirandello...! Como mis abuelos, viticultores y músicos anónimos... Y yo (en cierto modo, por lo que hace a la sangre inmigrante) que no tendré plaza en su Parnaso" (Di Benedetto, 2006: 344).

Aparece aquí un yo definitivamente humano, capaz de reflexionar, volver sobre sí mismo, pensar y pensarse, incluso como otro. Ponerse en el lugar del otro, en este caso el animal, en un intento por comprenderlo y aceptarlo, es parte inherente a la naturaleza humana. Sin embargo, el final del discurso, nuevamente en la voz de la especie, introduce un elemento que preocupa a Di Benedetto: la violencia, la violencia del hombre pero también, allí textualizada, su propia ambivalencia que no son sino dos caras de similar pasión, la de ser hombre:

Sólo que unas cuantas, sustraídas de las aguas por los pescadores, llegamos a conocer el fuego: la llama y la brasa con que se nos cuece. Tributo al depredador, al hambre del hombre, amo de la tierra. El fuego que nos aplica es uno de los tantos que enciende, incluso para alcanzar a sus semejantes. Con algunos mata y con otros ama. (Di Benedetto, 2006: 345)

Con magnífico lirismo, el texto nos presenta una clave central en la poética del autor (Varela, 2007b). En tanto hombre, puede pensar y es este un pensamiento creador, no meramente especulativo, ya que puede pensarse y, especialmente, sentir como otro. En su reflexión sobre lo humano, la violencia, la ambivalencia de lo humano, la constante oscilación entre el Bien y el Mal surgen una y otra vez. Pero es tanto el dolor que le provoca, que debe acudir al distanciamiento a través de lo animal -que es proyección pero también distanciamiento creativo- para poder insistir en lo que para él termina siendo el gran misterio de lo humano: la libertad de elección, la capacidad atormentadora de poder volcarse hacia uno y otro lado del fiel de la balanza.

\section{BIBLIOGRAFÍA}

CAMPOS, Mercedes.

1987 "Simbología animal dibedenettiana (fragmento)", Diario Hoy, Mendoza, 11 de octubre de 1987, sección "Cultura":3.

CHEVALIER, Jean y GHEERBRANT, Alain.

1991 Diccionario de los símbolos. Barcelona: Herder. 
DI BENEDETTO, Antonio.

1953 Mundo animal. Mendoza: D’Accurzio.

1957 Grot. Mendoza: D’Accurzio.

1961 El cariño de los tontos. Buenos Aires: Goyanarte.

1978 Absurdos. Barcelona: Pomaire.

1983 Cuentos del exilio. Buenos Aires: Bruguera.

2006 Cuentos completos. Buenos Aires: Adriana Hidalgo.

FILER, Malva.

1980 "Los animales simbólicos de Antonio Di Benedetto", en Rose Minc y Marilyn Frankenthaler (eds.). Requiem for the "boom"-premature? A Symposium. Montclair: N.J., Montclair State College, pp. 123-136.

1982 La novela y el diálogo de los textos. Zama de Antonio Di Benedetto. México: Oasis.

BOLDORI, Rosa.

1968 "Di Benedetto y las zonas de contacto", en Rogelio Barufaldi, Rosa Boldori y Eugenio Castellio. Moyano-Di Benedetto-Cortázar. Santa Fe: Ed. Crítica 68 y Colmegna, pp. 35-50.

MATURO, Graciela.

1987 "La aventura vital en la creación de Antonio Di Benedetto", en Di Benedetto, Antonio. Páginas de Antonio Di Benedetto seleccionadas por el autor. Buenos Aires: Celtia.

CORRO, Gaspar Pío del.

1992 Zama, zona de contacto. Córdoba: Ediciones Argos.

CASTELlinO, Marta Elena.

1998 Antonio Di Benedetto; renovador de la narrativa argentina, ensayo. Mendoza: Ediciones del Canto Rodado.

NÉSPOLO, Jimena.

2004 Ejercicios de pudor; sujeto y escritura en la narrativa de Antonio Di Benedetto. Buenos Aires: Adriana Hidalgo editora.

VARELA, Fabiana Inés.

2007a "El desierto viviente: el espacio regional en la narrativa breve de Antonio Di Benedetto", en Marta Elena Castellino (dir.). Literatura de las regiones argentinas II. Buenos Aires: Dunken, pp. 267-298.

2007b "Antonio Di Benedetto: una poética ética y humanística", en Víctor Gustavo Zonana (dir.). Poéticas de autor en la literatura argentina (desde 1950). Buenos Aires: Corregidor, pp. 105-141.

2010 "La aproximación al misterio en dos relatos de Antonio Di Benedetto", en Gustavo González Villanueva (dir.). Escritoras y escritores latinoamericanos; estudio y comentario: Leo-PiensoOpino. Vol. 18. San José de Costa Rica: Promesa Cultural, pp. 15-34.

ZARAGOZA, Celia.

1979 "Antonio Di Benedetto: 'El instinto de muerte es tema permanente en mis libros", El País, Madrid, 14 de enero de 1979, Sec. "Arte y pensamiento":IV-V. 